\title{
Equitable distribution of growth for utilitarian and non-utilitarian infrastructure planning
}

\author{
Arif Wismadi ${ }^{1} 2^{*}$, Mark Brussel $^{1}$, Mark Zuidgeest ${ }^{3}$ and Martin van Maarseveen ${ }^{1}$
}

\begin{abstract}
To simultaneously address social equity and spatial equity, we develop a new type of preference modelling to distribute infrastructure resources that takes into account neighbourhood inequity effects. We compare this so-called spatial preference modelling (SPM) with the more common non-spatial preference modelling (NSPM) in terms of their compliance to two distinct perspectives of welfare theory, i.e., utilitarian and non-utilitarian welfare theory. With respect to utilitarian theory, we apply a total utility equality approach, whereas for non-utilitarian equality, we conduct a curve dominance analysis to evaluate the effect on (1) pro-poor policy, (2) inequity and (3) prosperity. A case study for the Special Region of Yogyakarta in Indonesia is used to show the difference in the effectiveness of SPM and NSPM in resolving resource allocation problems in the fields of transportation, electricity, telecommunication and freshwater infrastructures, four fields of infrastructure that differ in terms of their typology (point, linear, plane and space), initial level of development and spatial inequity. The results confirm that SPM complies better with both welfare theories than NSPM. Moreover, the curve dominance analysis reveals that infrastructure characteristics and the level of development contribute to model effectiveness. Hence, the findings can contribute to a more effective policy for equitable growth.
\end{abstract}

Keywords: Preference modelling; SDSS; Social equity; Spatial equity; Utilitarian; Non-utilitarian; Infrastructure planning; Indonesia

\section{Background}

A long-term inequitable distribution of resources in a country often results in all various social issues (e.g., crimes and social tension). Indonesia has also been challenged by both social and spatial inequality issues. Since 1997-1998, when massive riots demanding political reform led President Suharto to step down, these issues have been driving continuous governance reforms to be more decentralized and aimed at equitable welfare among regions and social groups.

Infrastructure service is one of the instruments for distributing welfare and addressing social and spatial equity (equality of opportunity). Many countries, including Indonesia, have the option to deliver infrastructure service through either a state monopoly or a marketdriven pro-competitive mechanism. Meanwhile, the

\footnotetext{
* Correspondence: arif.wismadi@ugm.ac.id

${ }^{1}$ Faculty of Geo-Information Science and Earth Observation, University of Twente, Enschede, the Netherlands

${ }^{2}$ PUSTRAL (Center for Transportation and Logistics Studies), Universitas Gadjah Mada, Kemuning M-3, Sekip, Sleman, 55281 Yogyakarta, Indonesia Full list of author information is available at the end of the article
}

global liberalization trend has shifted some public service provision into a more market-driven orientation, allowing private industry to compete.

Among the four infrastructure sectors discussed here, in Indonesia, the provision and management of transportation infrastructure is still led by the government, but the landscape of mobility is determined by private companies and vehicle industries. The electricity sector has been introducing private investment opportunities for energy production, but the monopoly of state-owned enterprises for energy distribution is maintained. Water infrastructure is provided through local government enterprises, but they are operating in a competitive environment with global bottled drinking water industries. Telecommunication has been reformed from a state monopoly into a full liberal market for mobile services. In this case, no single infrastructure asset is owned by government, and development is driven by marketoriented private investment.

The market-driven approach has been shown to be efficient (Zhang 2014), and it has resulted in more

\section{Springer}


affordable services (Yigitcanlar and Lee 2014). However, the infrastructure roll-out tends to go to places where wealthy people or markets are concentrated (Sovacool 2013), thus leaving some areas and social groups unserved or underserved (Sager 2011). Meanwhile, state-owned enterprises, with their mandate for distributing equitable service among people and locations, including non-commercially feasible and remote areas, face difficulties setting cross-subsidy tariffs in a market-driven environment to allow for rural investment.

In such a case, market-driven policy has increased the problem of unequal service provision (Araral 2009) across people and spaces. Therefore, the government has reviewed the market-driven approach and applied measures to ensure a more equitable development. Such policies, that are implemented as so-called public service obligation (PSO) programs, e.g., for transportation, or universal service obligation (USO) programs, in the telecommunications and electricity sectors (i.e., the rural electrification program), have been strengthened with the introduction of the National Act No 25/2009 on Public Service to ensure equitable service among social groups and regions. These policy measures are managed by the government with funding support from industry and the state budget.

The attempt to reach an equitable welfare distribution through sector reforms and decentralized actions has been in place for almost two decades. However, inequity has continued to increase, as indicated by a rise in the Gini Index of income distribution from 0.335 to 0.413 between 1996 and 2013 (BPS 2014). This indicates that the implemented policies, being either "people centred" (as in market driven) or "place based" (addressing regional disparity) did not sufficiently address equitable growth. Decades of continuous inequity have also revealed the absence of proper information and decision mechanisms to allocate resources to target groups or locations. Such mechanisms are critical to support a resource distribution under a constrained budget, progress monitoring, and more importantly are a means to formulate effective policy for prioritizing allocation.

The knowledge of addressing equity issues in decisionmaking requires a theory of social choice and an applicable method of preference modelling that simultaneously addresses equitable social and spatial distributions. In decision support systems (DSS), such preference modelling (PM) refers to a routine that aims to model stakeholder preferences into priority making for selecting certain options, or to locate the allocation of resources (Tsoukias 1991; Perny and Roy 1992; Benferhat et al. 2006; Piccolo and D'Elia 2008; Roberts and Tsoukiás 2009).

To address inequity issues, discussions on the concept of fairness in the distribution of resources and welfare have been going on for decades (Smith 1977; Sen 1980; Dworkin 1981a, b; Nussbaum 2003; Sen 2004; Sudgen
2006; Qizilbash 2011). For example, David Marshall Smith and Amartya Sen started the debate in which they questioned the moral philosophy of fairness behind the equality of distribution already in the late 1970s.

Whereas Smith (1977) questioned the lack of moral concern in the geographical distribution of welfare, Sen (1980) argued that the established concept of equality, which is based on utilitarian theory, has limitations in securing fairness. The most serious limitation, he argued, is the non-compliance to pro-poor policy, particularly if the planner employs equality of marginal utility. This measure attempts to equalize the satisfaction (marginal utility) between the rich and the poor for each unit of additional resources. Naturally, the rich demand more than the poor, and as an implication, more resource goes to the rich.

The alternative measure in utilitarian theory is that of equality of total utility, where the planner aims to maximize the total utility of resource distribution (Maniquet 2004). In such a case, as the poor are more easily satisfied; priority is given to the poor to maximize the total utility.

Sen (1980) also introduced an alternative measure for a non-utilitarian model. He introduced a capability approach that aims to measure additional capability, instead of satisfaction, due to a distributed resource. Hence, a non-utilitarian would focus more on increased capability through the provision of equality of opportunity (Maniquet 2004).

Those approaches have provided a good basis for measuring equality among social groups, but less attention has been given to aspects of spatial inequity, i.e., to the measurement of equality between areas or regions. Most inequality measurements (Eliazar and Sokolov 2012), social welfare functions (Dolan and Tsuchiya 2009) and preference modelling (Domshlak et al. 2011) address only social equality, whereas spatial inequality can contribute to large problems for society, e.g., concentrations of crime (Wang and Arnold 2008) or increased health risks (Chandola 2012). Some previous works have tried to include such spatial features in resource allocation (Cloke et al. 2001; Chakhar and Mousseau 2007; Bissonnette et al. 2012). However, these methods again do not look at social equity issues. Hence, using only one of these approaches, decisions may overlook the social or spatial dimension of the inequity problem.

To simultaneously address social and spatial equity, Wismadi et al. (2013) proposed a new type of preference modelling to allocate resources by explicitly taking neighbourhood inequity into account. Here, this spatial preference modelling (SPM) addresses equity not only among people but also across locations. In accordance with this concept, priority will be given to addressing the inequity of two persons at a closer distance than two 
others who have a similar level of inequality but live further apart. This model has been shown to be able to effectively address spatial equality in the case of transportation infrastructure. However, the compliance of the result to a more general moral philosophy of fairness, i.e., following Sen (1980), still needs to be investigated.

The purpose of this study is therefore to compare spatial preference modelling (SPM) with the more common nonspatial preference modelling (NSPM) for resource allocation in terms of its compliance to two distinct theories of welfare (i.e., utilitarian vs non-utilitarian welfare) and evaluate its practical implication to improve the effectiveness of resource allocation policy for infrastructure development.

The next section explains the methods for resource allocation and equity measurement. The third section reports the results of the simulation, and the fourth section discusses the important findings of this study and discusses the implications for policy implementation. The last section concludes.

\section{Methods}

We compare the compliance of SPM and NSPM to the principle of equity, as proposed in both utilitarian and non-utilitarian theories. To learn their practical implications, both preference modelling approaches are applied to resource allocation for four different types of infrastructure (i.e., roads, electricity, telecommunications and water). As shown in Table 1, each of them has a different network typology; i.e., roads: linear; electricity: linear; telecommunications: a combination of linear (fibre optic and copper fixed lines) and space (mobile networks); and water: a combination of linear (freshwater pipe) and space (ground water sources) all have different typologies. The simulation is developed for scenario-based rather than optimisation-based applications. Hence, a 'what if' type of question relating to policy objectives, is more appropriate rather than to provide the model user with the 'best' option under given criteria. However, to demonstrate how the algorithm is capable to perform iteration mechanisms toward an optimisation-based applications, a two-step iteration is also demonstrated and observed in this research. Hence, two what-if scenarios of simulation are performed, first by assigning one target growth applied in one simulation, then secondly, by assigning half of the target growth applied in a two-step iterative simulation.

Table 1 The data set

\begin{tabular}{|c|c|c|c|c|c|}
\hline Types of data & $\begin{array}{l}\text { Unit of } \\
\text { measurement } \\
\text { for the model }\end{array}$ & $\begin{array}{l}\text { Data } \\
\text { sources *) }\end{array}$ & $\begin{array}{l}\text { Unit of } \\
\text { measurement in } \\
\text { the data source }\end{array}$ & Data conversion & Systems Characteristics \\
\hline \multicolumn{6}{|l|}{ Infrastructure: } \\
\hline Transport & $\begin{array}{l}\text { Average travel } \\
\text { speed }(\mathrm{km} / \mathrm{h})\end{array}$ & $\begin{array}{l}\text { PODES } \\
\text { code } 9022 \\
9023\end{array}$ & $\begin{array}{l}\text { (distances KM, } \\
\text { travel time HR) }\end{array}$ & $\begin{array}{l}\text { Average travel speed to } \\
\text { facilities }(9022 / 9023)\end{array}$ & $\begin{array}{l}\text { The system is formed by a linear type of } \\
\text { infrastructure. Mobility relies on private vehicle with } \\
\text { limited public transport in urban areas. Low } \\
\text { performance indicates traffic jam (urban) and a } \\
\text { poor state of infrastructure (rural). }\end{array}$ \\
\hline Electricity & $\begin{array}{l}\text { Average } \\
\text { electricity } \\
\text { supply per } \\
\text { household (VA) }\end{array}$ & $\begin{array}{l}\text { PODES } \\
\text { code } 501\end{array}$ & (Electrified HHs) & $\begin{array}{l}\text { Weighted average of } \\
\text { electricity supply for poor } \\
\text { and non-poor. }\end{array}$ & $\begin{array}{l}\text { The system is formed by a linear type of } \\
\text { infrastructure. The network is laid along the road } \\
\text { network. High performance indicates urban and } \\
\text { more developed villages. }\end{array}$ \\
\hline Telecom & $\begin{array}{l}\text { Average data } \\
\text { transfer } \\
\text { capacity (kbps) }\end{array}$ & $\begin{array}{l}\text { PODES } \\
\text { codes 904, } \\
911\end{array}$ & $\begin{array}{l}\text { (Connected HH to } \\
\text { fix line, Mobile } \\
\text { network } \\
\text { coverage) }\end{array}$ & $\begin{array}{l}\text { Weighted average of data } \\
\text { transfer capacity of fixed } \\
\text { line and mobile networks. }\end{array}$ & $\begin{array}{l}\text { The system is formed by a combination of linear and } \\
\text { space types of infrastructure. The networks of linear } \\
\text { systems rely on fiber optic (urban center) and copper } \\
\text { (urban to sub-urban) along the road networks. The } \\
\text { wireless mobile networks extend a space type of net- } \\
\text { work to reach market in rural area.. }\end{array}$ \\
\hline Water & $\begin{array}{l}\text { Average } \\
\text { discharge (litre/ } \\
\text { day) }\end{array}$ & $\begin{array}{l}\text { PODES } \\
\text { code } 608\end{array}$ & $\begin{array}{l}\text { (type of source, } \\
\text { electrification) }\end{array}$ & $\begin{array}{l}\text { Water discharge capacity } \\
\text { based on each type of } \\
\text { source. }\end{array}$ & $\begin{array}{l}\text { The system is formed by a combination of point, } \\
\text { linear and space types of infrastructure. Urban area } \\
\text { served by linear public fresh water with option to } \\
\text { private wells as the water source. Underground } \\
\text { water forms space type of infrastructures. Point } \\
\text { infrastructures are found in dry areas lacking water } \\
\text { sources (white cluster in Fig. 1). }\end{array}$ \\
\hline \multicolumn{6}{|l|}{ Demographic: } \\
\hline Population & $\begin{array}{l}\text { Number of } \\
\text { Population in } \\
\text { the village }\end{array}$ & $\begin{array}{l}\text { PODES } \\
\text { code } 401 a, b\end{array}$ & $\begin{array}{l}\text { (male pop, female } \\
\text { pop) }\end{array}$ & $\begin{array}{l}\text { Total population } 401 \mathrm{a}+ \\
401 \mathrm{~b}\end{array}$ & $\begin{array}{l}\text { Population is distributed in flat areas which are } \\
\text { historically fertile or recently served with } \\
\text { infrastructure, especially road networks and } \\
\text { economically more developed areas. }\end{array}$ \\
\hline
\end{tabular}


With such purpose, the allocation model in this study aims to distribute a target growth of infrastructure service performance for each location rather than directly determine the amount of distributed resources, such as monetary units or construction materials. Resource allocation in this study refers to a percentage of the target growth of performance, which later could be achieved with increasing investment or operational expenditure to reach the targeted performance in the respected location. Here, we do not calculate the actual amount of resources that need to be allocated.

The spatial unit in this study is a village, the lowest administration unit, below a province or a district, for which we set a target of an additional level of service. The target in this experiment is a $10 \%$ growth from the current level of infrastructure performance. With the objective of addressing inequity, some villages receive more priority and an increased service level higher than $10 \%$, whereas others might receive less than $10 \%$ growth compared to the initial service level.

This allocation can be illustrated by looking at national level development policies, where a government-or politicians during election periods-often declare a target economic growth of, for example, $10 \%$. This $10 \%$ growth is often cited as the "2-digit" optimistic target of national development (Yuan et al. 2008; Chen 2010; Ohana 2010). This aggregate target of $10 \%$ at a national or district level must somehow be implemented in lower administrative units. This target growth distribution should not simply be applied with $10 \%$ growth of each village because the poorest village would receive an absolute value that is lower than the $10 \%$ growth of the richest. If more resources are allocated to the rich than to the poor, the allocation would not comply with a sense of fairness.

Spatial preference modelling (both SPM and NSPM) has been formulated to give priority to the poor, and it aims to reduce the inequality amongst them. By introducing spatial proximity as the preference factor in SPM, the spatial patterns of the location of allocated resources will be distinct from NSPM. In SPM, more priority is given to addressing the inequality of two villages at a closer distance than two others at the same levels of inequality but located at a further distance. By contrast, in NSPM, the priority for growth will consider only the inequality level amongst villages and disregard the distance between the compared villages. The variations in the target growth distribution from the two models are the basis for comparing SPM and NSPM with respect to the effectiveness of achieving the objectives of utilitarian and non-utilitarian approaches.

The framework of this research is outlined into the three common stages of decision-making processes (Simon 1960), i.e., the intelligence (specify decision problems and objectives), design (generate an alternative solution) and choice stages (evaluate and recommend the solution), as summarized in Fig. 1.

\section{Study area and data}

Indonesia is a vast archipelago that comprises over 17,000 islands form a land mass of $1,919,440 \mathrm{~km}^{2}$ populated by 253 million inhabitants (Rowley and Abdul-Rahman 2008). To move towards equitable growth, in addition to focusing on the main national infrastructure networks, various village-level programs are also implemented, e.g., a rural electrification programme (Outhred and Retnanestri 2015; started in the 1970s with more than USD 200 million annually) and a rural telecommunications USO program (since 2010 in more than 35,000 villages with approximately USD 500 million annually, which has been expanded with a Presidential Decree $96 / 2014$ as the Indonesia Broadband Plan). In other sectors, such as roads and water supply, there are community-based infrastructure programmes, i.e., the Kecamatan Development Programme (KDP), which are financed by the World Bank (USD 1.2 billion), which began in 1998 and were aimed at 28,000 villages (Das 2015). Kecamatan is a sub-district administration level in Indonesia. There are more than 4,000 sub-districts in the country. On average, a sub-district contains 20 villages and has a population of over 50,000 people.

Our study area, the Special Province of Yogyakarta, Indonesia (Fig. 2), is one of the targets of those programmes. Populated with approximately 3.4 million people, it consists of 438 villages, with an average of 5,632 inhabitants each. The average size of a village is $724.43 \mathrm{ha}$ with a minimum of 26.57 ha in urban areas and a maximum of 2,890.36 ha in more rural areas (BPS 2006).

We use a village-level dataset from 2005 called PODES (Potensi Desa/Village Potency; BPS 2006), which consists of approximately 400 attributes linked to demographics, socio-economic activities and infrastructure, but we select only attributes that are relevant to infrastructure. These data and their units of measurement are presented in Table 1.

\section{Calculations in preference modelling}

Preference models typically include a decision rule based on a difference of ranking between two objects. For comparing objects, the common linear scale transformation method is applied to convert the original criterion scores into standardized scores of utility (Xiang 2001; Malczewski 2004; Ananda and Herath 2009).

Such a method uses two types of preference criteria. The first one defines the benefit criteria, which refers to a stakeholder's preference for the highest raw score. (Higher scores are more preferable.) The second defines cost criteria, which refers to a stakeholder's preference 


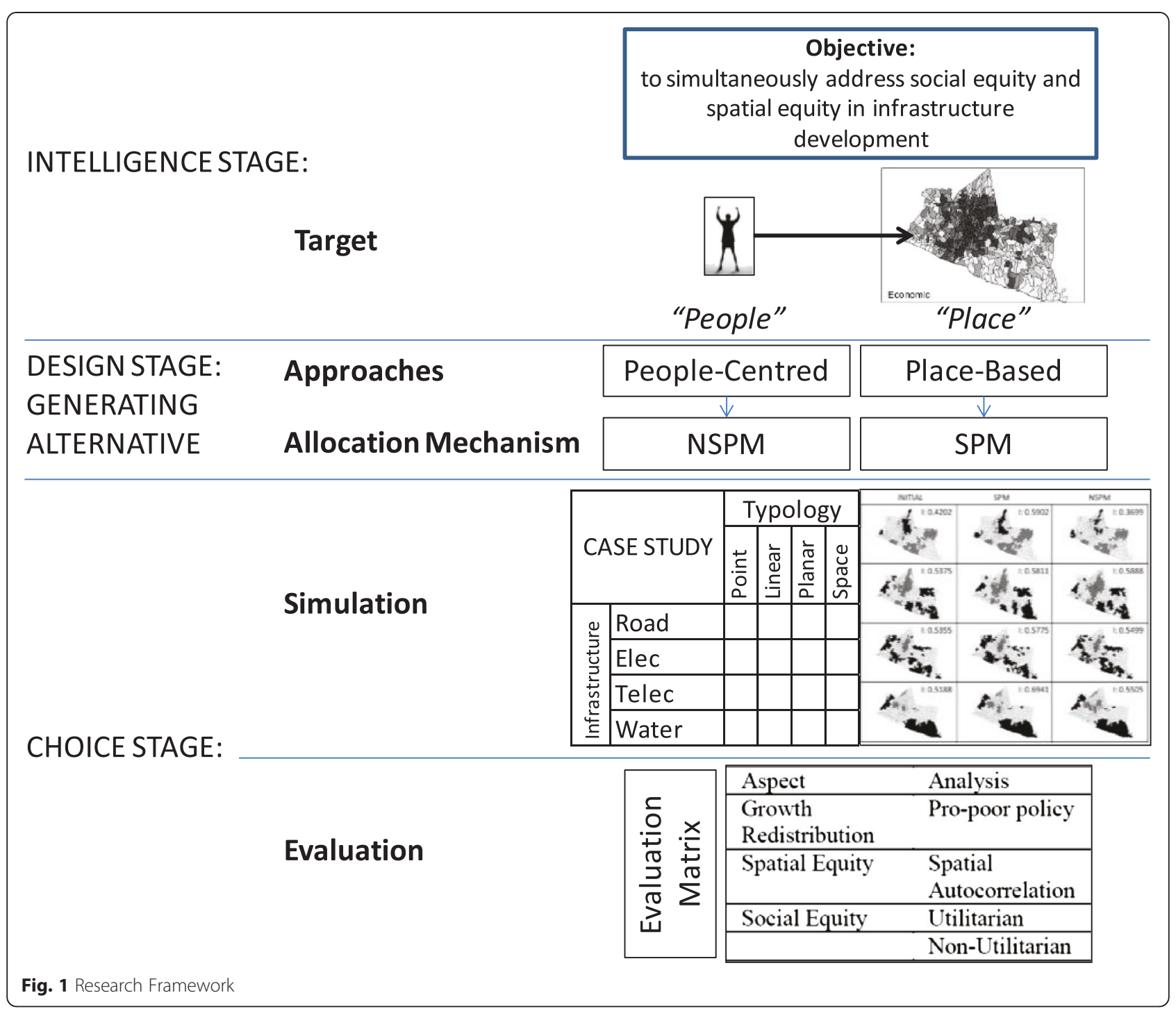

to choose the object with the lowest raw score. (Lower scores are more preferable.)

\section{Standardization without spatial neighbouring comparison features}

The three common types of standardization procedures are maximum, interval and goal standardization (Beedasy and Whyatt 1999; Xiang 2001; Phua and Minowa 2005; Ananda and Herath 2009). Maximum standardization ensures that the standardization values are proportional to the original values with the 0 values equal to the absolute 0 in the original score. Interval standardization produces a score that is normalized with a linear function between the absolute lowest score and the highest score, which implies a relative scale, and aims to exaggerate the differences. Exaggeration is often required when a slight value of differences is considered critical. Goal standardization is similar to interval standardization; however, it assigns specific reference points within the range of unit $i$ scores as an ideal or goal value and a minimum or maximum value acceptable by decision makers.

While we focus on the pro-poor objective, we want to exaggerate the differences between the poorest and the richest. Hence, we use interval standardization and apply the cost criteria to prioritize the poorest (equation [1]).

$$
P_{i}=-\left(\frac{x_{i}-\min x}{\max x-\min x}\right)+1
$$

where:

$P_{i}=$ the priority score for unit $i$, the unit is a spatial target for resource location-allocation.

$x_{i}=$ the score of unit $i$

$\max x=$ the highest absolute score in dataset $x$

$\min x=$ the lowest absolute score in dataset $x$ 


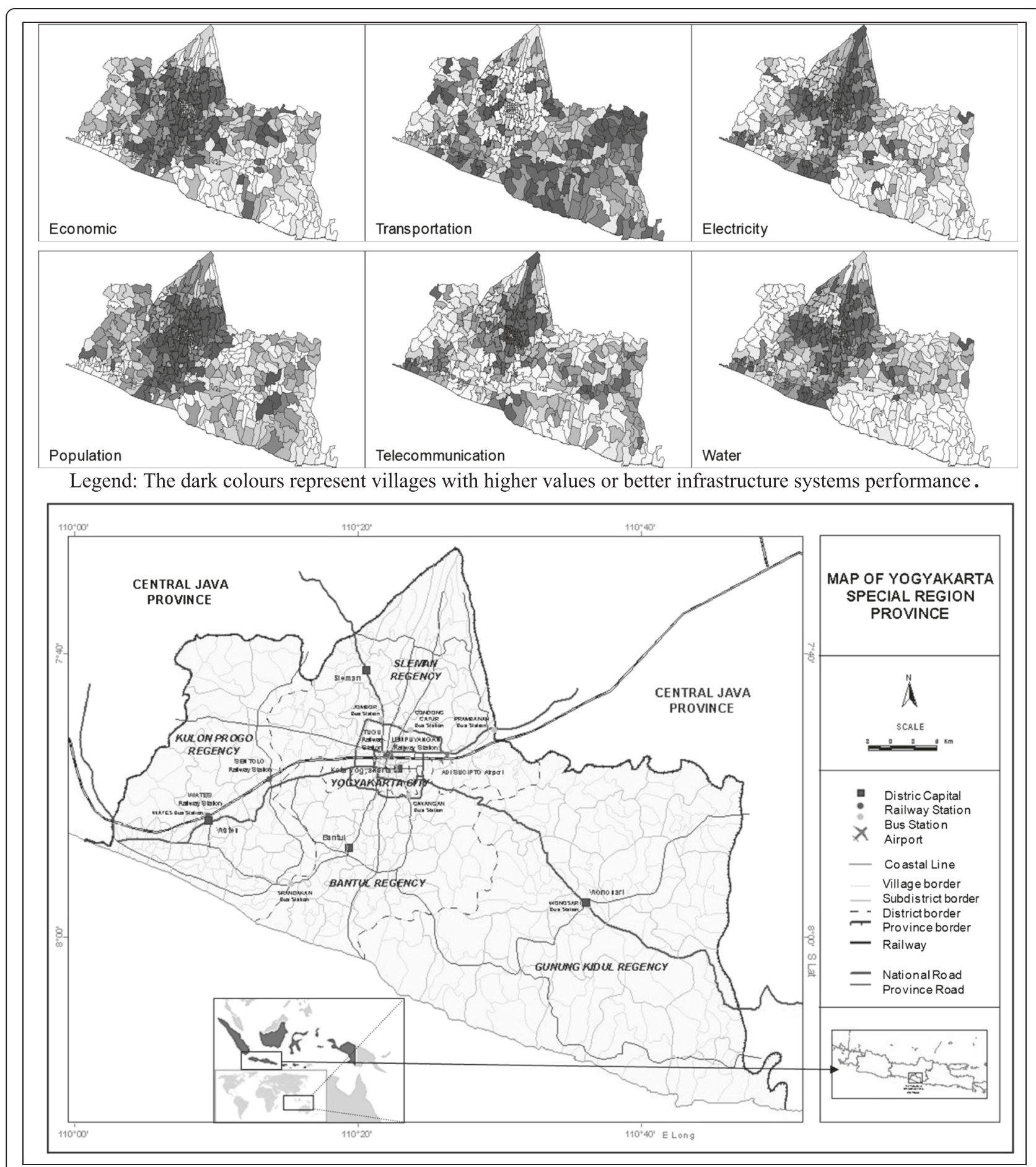

Fig. 2 The Special Province of Yogyakarta, Indonesia, consisting of 438 urban and rural villages. Note: The urban area is at the centre of the radial road networks. The dark colours represent villages with higher values or better infrastructure system performance

Standardization with inclusion of spatial neighbourhoodcomparison features

To include spatial equity measures, Wismadi et al. (2013) extended the standardization procedures into global, glocal and local spatial standardization. A global spatial standardization compares inequity with the reference of one value within the study region. Accordingly, the glocal spatial standardization measures the inequity 
with the average value from the region. Local spatial standardization then focuses on addressing inequity among neighbouring units.

Here, we aim to address local inequity. Priority is given to the unit with the highest neighbouring inequality score, with absolute zero as a reference. When unit $x$ has higher performance than its neighbouring units, we set the level of inequality as zero, meaning that we will not prioritize the allocation of resources to this unit.

We describe the neighbouring values of $x$ at village $i$ as the spatial lag variable $W_{-} x_{i}$. Spatial lag refers to a lag or value differences of the same variables on its connected neighbouring location. Connectivity is defined by physical connectivity (e.g., the availability of bridges or roads between villages), spatial proximity (distance) or another type defined in the connectivity rule. Hence, spatial lag is calculated by averaging all values of neighbouring polygons of $x_{i}$ using a neighbourhood connectivity rule for the weights $W_{i j}$, that represent connectivity between neighbouring units of $j$; i.e.,. $W_{i j}=1$ if locations $i$ and $j$ are adjacent or connected and zero otherwise (also $W_{i i}=0$ because as a village cannot be adjacent to itself).

Because we prefer to allocate to a unit that has higher gaps than its neighbour, we apply the benefit criteria of local maximum standardization as follows:

$$
P_{i}=W_{i j}\left[\frac{x_{\operatorname{lag}_{i}}}{\max x_{\operatorname{lag}_{i}}}\right]
$$

$P_{i}=$ the priority score for unit $i$, the unit is a spatial target for resource location allocation.

$W_{i j}=$ represents the connectivity between $i$ and its neighbouring units of $j$

$x_{\text {lagi }}=$ denotes the local inequity of $W_{-} x_{i}-x_{i j}$ however, if $W_{-} x_{i}-x_{\dot{v}}<0, x_{\text {lagi }}$ will be defined as 0 .

$\max x_{\text {lagi }}=$ denotes the maximum local inequity of $W_{-} x_{i}-x_{i}$.

\section{Procedure for location-allocation}

We use the priority-score for unit $i, P_{i}$, obtained from preference modelling, to allocate target growth for each

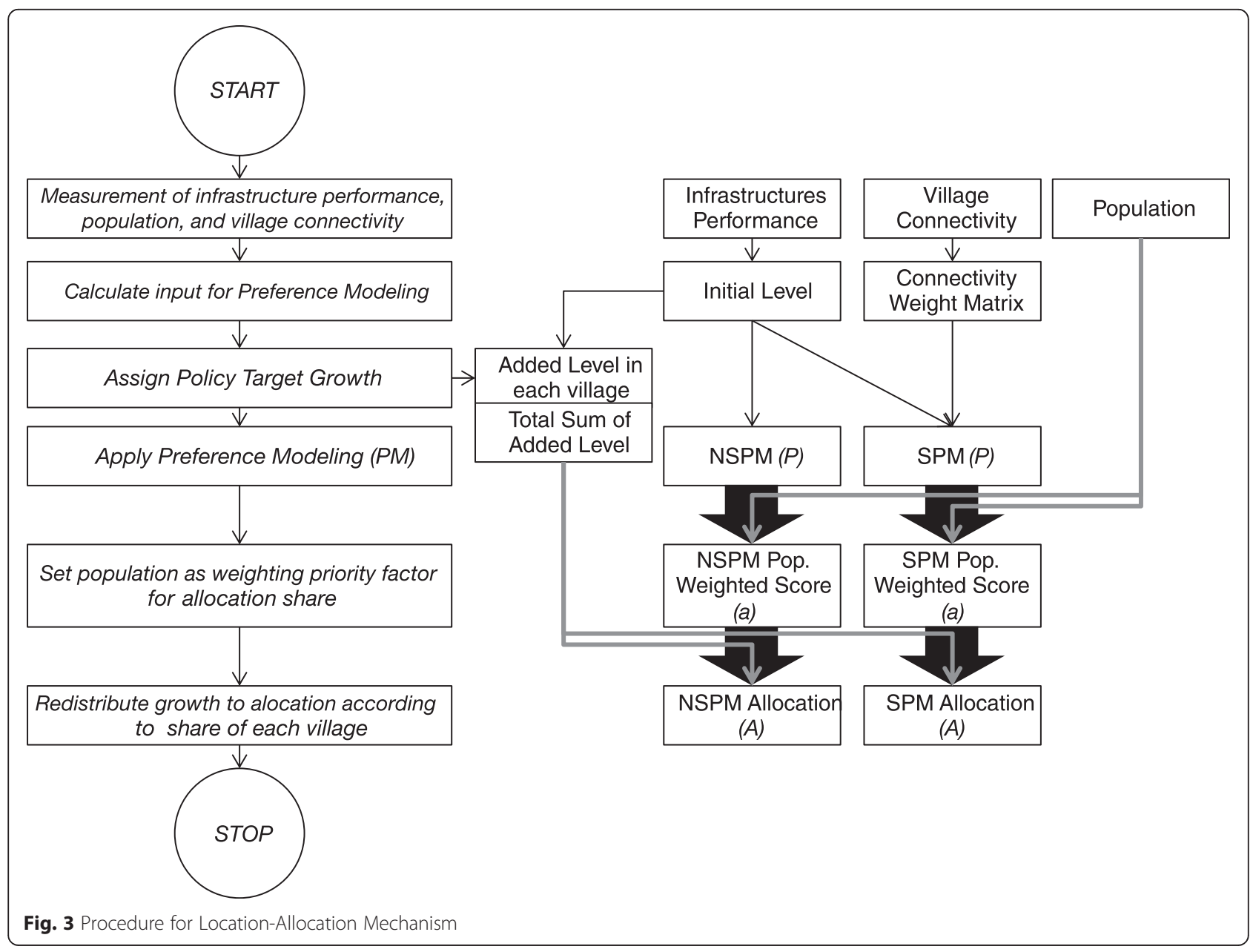


respective unit. To locate the allocation, the scores from the preference modelling are weighted with the population in each village (equation [3]):

$$
a_{i}=\frac{P_{i} \cdot Q_{i}}{\sum_{i} P_{i} \cdot Q_{i}}
$$

$P_{i}=$ score of priority of village $i$ from the preference modelling (0 to 1$)$, obtained with equations (1) and (2)

$Q_{i}=$ population of village $i$ (population)

$a_{i}=$ percentage share of the sum of total additional resources in the region allocated to village $i$ (\%)

To obtain equitable growth, with the given $10 \%$ growth, we first sum the total additional absolute values from all villages, as $A$, and then, those amounts are redistributed to each village according to the priority score $\left(a_{i}\right)$ from equation [3]. Generally, some villages (the poorer villages) obtain more than $10 \%$ of the initial allocation, whereas for richer villages, a lower percentage is provided.

Finally, the location-allocation for each village $i$ is provided with:

$$
A_{i}=a_{i} \cdot A
$$

$A_{i}=$ allocated absolute value of improved level of service for village $i$ (the units refer to performance indicators in Table 3)

$a_{i}=$ percentage share of the sum total additional resources in the region allocated to village $i$ (\%)

$A=$ sum total additional absolute values of improved level of service from all villages from the region (the units refer to performance indicators in Table 3)

Figure 3 summarizes the location-allocation mechanism applied for both NSPM and SPM,

\section{Equity measurement}

\section{Spatial equity analysis}

We apply a spatial autocorrelation approach to evaluate spatial equity. This approach simultaneously addresses both location and attribute information, thus creating a powerful analytical technique (Tsou et al. 2005). Here, we use Moran's I method, which is commonly applied for evaluating spatial equity (Lorant et al. 2001; Tsou et al. 2005; Grubesic 2008). Moran's $I$ is positive when nearby objects tend to be similar and suggests an equitable distribution, where Moran's $I=1$ is the most equitable distribution. On the contrary, Moran's $I$ is negative when the object values tend to be more dissimilar than what is normally expected, with Moran's $I=-1$ being the most inequitable distribution. Moran's $I=0$ when attribute values are arranged randomly and independently in space.

A direct extension of the Moran scatter plot can be viewed as a map of the Local Index of Spatial Autocorrelation
(LISA; Anselin 1995). The resulting map locates the clusters of similarity (spatial equity) or dissimilarity (spatial inequity).

\section{Total utility to measure utilitarian equality}

With utilitarian theory, the equality objective is to maximize the total utility. Hence, a higher total utility indicates compliance with the objective. This measurement is done by estimating the marginal utility or satisfaction to one additional unit of resource and summing up the total utility generated by the distributed resource.

Referring to the Arrow-Pratt relative risk aversion formula (Damodaran 2008), we apply the first derivative of utility to the wealth of the $\log$ utility function of $U=$ $\ln (W), U^{\prime}=1 / W$ to measure how utility changes as wealth $(W)$ changes. Hence, the estimate of marginal utility $U^{\prime}$ or $\mu U$ for an amount of allocated resources $Q$ at village $i$ with an existing level of available resources (wealth) of $X$ is:

$$
\mu U_{1}=Q_{i} / X_{i}
$$

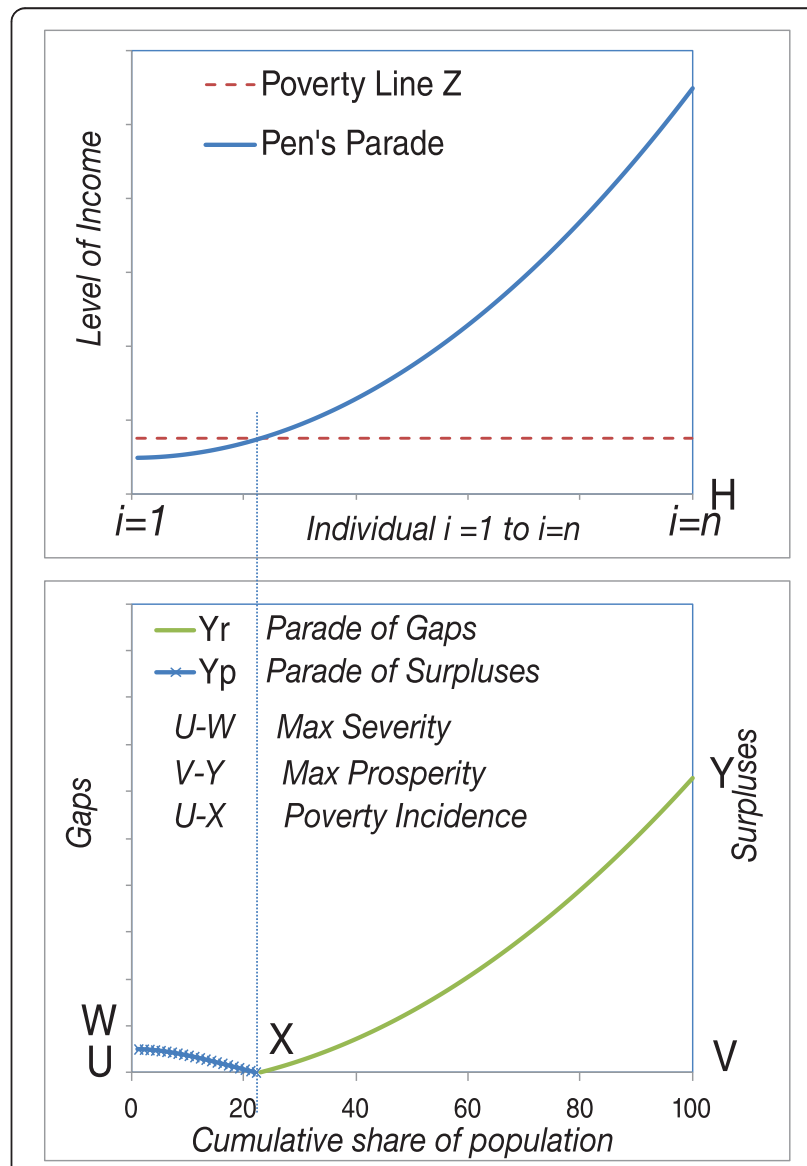

Fig. 4 Original Pen's parade (above) and V-curve parade of gaps (Yp) and surpluses (Yr) (below) 
Table 2 Indices of non-utilitarian equality measure

\begin{tabular}{lll}
\hline No & Indices & Descriptions \\
\hline 1 & $\begin{array}{l}\text { Poverty } \\
\text { Incidence }\end{array}$ & $\begin{array}{l}\text { Percentage of "the poor" (population living under } \\
\text { poverty line Z) }\end{array}$ \\
2 & $\begin{array}{l}\text { Poverty } \\
\text { Severity }\end{array}$ & $\begin{array}{l}\text { Maximum severity burden by the poorest (unit in } \\
\text { utils, which is a hypothetical unit measuring } \\
\text { satisfaction), representing the amount of additional } \\
\text { effort for the poorest to reach the poverty line }\end{array}$ \\
3 & $\begin{array}{l}\text { Poor } \\
\text { Inequality }\end{array}$ & $\begin{array}{l}\text { Gini inequality among "the poor". } \\
\text { Rich }\end{array}$ \\
$\begin{array}{l}\text { Inequality } \\
\text { Prosperity }\end{array}$ & $\begin{array}{l}\text { Gini inequality among "the rich". } \\
\text { Maximum prosperity enjoyed by the richest, } \\
\text { above the level of poverty line. }\end{array}$ \\
\hline
\end{tabular}

With this formula, the same amount of $Q$ will result in a lower $\mu U$ at a higher level of $X$ The total utility (TU) (equation [6]) can then be calculated by summing the product of $\mu U$ and the number of households $(H)$ in village $i$. The total utility for two or more distributions can then be compared.

$$
T U=\sum_{i=1}^{i=n} \mu U_{i} . H i
$$

\section{Curve dominance analysis for non-utilitarian equality measure}

The non-utilitarian approach evaluates changes in the level of opportunity and the effect on the poor and the rich using curve dominance analysis. The analysis employs a graphical method to compare distributional curves, as in Son and Kakwani (2008), formed by ordering the index from the worst off to the best off (Sen 1980). Curve dominance analysis can visually be interpreted in combination with its quantitative measure, e.g., the Lorenz Curve with the Gini Index (UNDP 2008).

To measure the equality of opportunity, a poverty line is required to indicate the basic capability needed and to decompose distribution patterns into areas below and above the poverty line (Yitzhaki 2002).

Pen's Parade is one graphical method that introduces a poverty line (Pen 1971). The curve represents a parade of every person in the economy walking by, as if in a parade, arranged by order of income, with the lowest incomes (dwarfs) at the front and the highest (giants) at the back
(UNDP 2008). With a poverty line, we can calculate the number of poor people (poverty incidence) and the situations of the poor (gaps) and the rich (surpluses).

To accurately measure the sense of equity, with reference to the poverty line, the calculation should recognize the sense of severity of poor people and the enjoyment of surplus by rich people. Recognition of this asymmetric shape of the poverty gap on the poor side versus the prosperity surplus on the wealthy side is important in equity measurement (Berrebi and Silber 1989)

To meet this requirement, we propose a new graphical method: a derivation of Pen's Parade into a parade of gaps and surpluses, as described below.

Let $y_{1}, y_{2}, \ldots, y_{n}$ be the individual incomes of $n$ incomereceiving units arranged such that $y_{1} \leq y_{2} \leq \ldots \leq y_{n}$, in which case, rank $\left(r_{y}\right)$ of the lowest income is 1 , and that of the highest income is $n$. Then, graphically, we modify Pen's Parade by applying the translation $y=y_{i}-z$, where $z$ represents the poverty line. Next, for the left part of the curve (with the negative values), we apply the reflection of the curve with the horizontal axis. As a result, we obtain a modification of Pen's parade as a parade of gaps (on the left-hand side) and surpluses (on the right-hand side) in a V-shaped curve.

To enable curve comparison, the rank $\left(r_{y}\right)$ on the horizontal axis is transformed as cumulative share of the population; hence, it shows the percentages of the population below the poverty line (the poor) and above the poverty line (the rich).

To recognize the asymmetric shape of gaps and surpluses, as suggested by Berrebi and Silber (1989), we then normalize both parts of the V-curve in two different ways. For the left-hand part, i.e., the gaps, we use:

$$
Y p_{i}=\left(z-y_{i}\right) / y_{i} \text { or } Y p_{i}=\left(z / y_{i}\right)-1
$$

The variable $Y p_{i}$ reflects the effort that "the poor" should exert to reach the poverty line. This normalized value of gaps also reflects the level of severity.

The right-hand side of the V-curve, i.e., the surpluses, are normalized with:

$$
Y r_{i}=\left(y_{i}-z\right) / z \text { or } Y r_{i}=\left(y_{i} / z\right)-1
$$

Here, $Y r_{i}$ reflects the extra opportunities enjoyed by

\begin{tabular}{|c|c|c|c|c|c|}
\hline Infrastructure & Performance Indicators & References & Basic Service & Domestic Activity & $\begin{array}{l}\text { Income } \\
\text { Generating Activity }\end{array}$ \\
\hline Transport & Average travel speed (km/h) & 534/KPTS/M/2001 & 10 & 15 & 20 \\
\hline Water & Discharge (Itr/day) & 534/KPTS/M/2001 & 30 & 125 & 220 \\
\hline Telecom & Data transfer capacity (kbps/pop) & USO Program BTIP, 2009 & 14.4 & 28.8 & 56 \\
\hline Electricity & Electricity supply per household (VA) & TDL PLN & 30 & 450 & 2200 \\
\hline
\end{tabular}
"the rich". This normalized surplus indicates the

Table 3 Minimum service level of domestic activity as the poverty line 
Table 4 Evaluation matrix

\begin{tabular}{|c|c|c|c|}
\hline Aspect & Analysis & Measure & Indicators \\
\hline Growth Redistribution & Pro-poor policy & Pro poor growth redistribution & Higher average of redistributed growth \\
\hline Spatial Equity & Spatial Autocorrelation & Cluster of similarity or dissimilarity & $\begin{array}{l}\text { Higher Moran's I index that indicate cluster } \\
\text { of similarity }\end{array}$ \\
\hline \multirow[t]{6}{*}{ Social Equity } & Utilitarian & Maximize total utility equality & Higher summation of marginal utility \\
\hline & Non-Utilitarian & Effectiveness to Poverty reduction & Lower Poverty Incidence \\
\hline & & & Lower Poverty Severity \\
\hline & & Equality of allocation & Lower Poor Inequality \\
\hline & & & Lower Rich Inequality \\
\hline & & Effectiveness to Prosperity & Higher Maximum Prosperity \\
\hline
\end{tabular}

prosperity level. The original and modified Pen's parade are illustrated in Fig. 4.

In this paper, we limit the evaluation of the effect on pro-poor policy, inequity and prosperity. Hence, the selected indicators are poverty incidence, poverty severity, inequality among the poor, inequality among the rich, and prosperity (see Table 2 ).

To set the poverty line, we use the standard of the minimum service level in the Ministry Decree for Settlement and Regional Infrastructure No 534/KPTS/M/ 2001, USO Program 2009 and the Pricing Category of Electricity from SOE (PLN; Table 3). Toward the capability of income-generating activity, we set the poverty line at the service level for domestic activities. We also assume that people living in the same village have equal levels of opportunities.

\section{Results}

This section reports the comparison of SPM and NSPM to allocate the "10\% growth target" in two what-if scenarios; $(1 \times 10 \%)$ and $(2 \times 5 \%)$ simulations. It reviews the pro-poorness of the growth redistribution, reports the spatial equity evaluation and finally reflects on the compliance of preference modelling to moral philosophy in utilitarian and non-utilitarian welfare theories. The results are outlined using the evaluation matrix in Table 4.

In terms of the pro-poorness of the allocation, the comparison of the level of redistributed growth reveals that with $10 \%$ growth, the SPM indicates a higher level of redistributed growth for all types of infrastructure than with NSPM, as shown in Table 5 . The results of both $(1 \times 10 \%)$ and $(2 \times 5 \%)$ based simulations also consistently provide similar finding.

A redistribution of growth, which is much higher than $10 \%$, indicates that the preference model successfully distributes most of the growth to poorer groups. In Table 5, the telecommunications and water infrastructures require a redistributed growth much higher than $10 \%$, which indicates a high level of social inequity, and the poorer groups demand more than the regional target growth. The higher value in SPM also indicates that addressing social inequity in a location with a neighbourhood disparity could increase the average of redistributed growth. This result indicates that more attention should be given to spatial inequity.

\section{Effect on spatial equity}

To compare the initial level of spatial equity and the changes due to SPM and NSPM, Fig. 5 shows LISA maps and its Moran's I values. It indicates the locations of spatial inequity (e.g., low-high, the poor surrounded by the rich, or high-low, the rich surrounded by the poor) and the locations of spatial equity among the rich (high-high) or among the poor (low-low).

In general, SPM results in higher Moran's I values (closer to 1 ) than NSPM. The $2 \times 5 \%$ scenario also indicate that SPM systematicaly improve the spatial equity. The improved equity with SPM is logical; it aims to focus more on addressing spatial inequity. On this ground, it can be said that SPM better locates a poor connection or missing link of intervillage infrastructures.

\section{Effect on social equity \\ Utilitarian}

Under utilitarian equity, with a $10 \%$ growth redistribution, the SPM also results in a higher sum total of marginal utility to all types of infrastructure, as shown in

Table 5 Average redistributed growth

\begin{tabular}{lllll}
\hline & Growth: & $1 \times 10 \%$ & Growth: & $2 \times 5 \%$ \\
\hline Sectors & SPM & NSPM & SPM & NSPM \\
ROAD & $17.7 \%$ & $15.0 \%$ & $8.8 \%$ & $7.5 \%$ \\
ELECT & $13.1 \%$ & $11.3 \%$ & $6.6 \%$ & $5.6 \%$ \\
TELEC & $52.2 \%$ & $40.1 \%$ & $26.3 \%$ & $20.1 \%$ \\
WATER & $17.3 \%$ & $14.8 \%$ & $8.7 \%$ & $7.4 \%$ \\
\hline
\end{tabular}




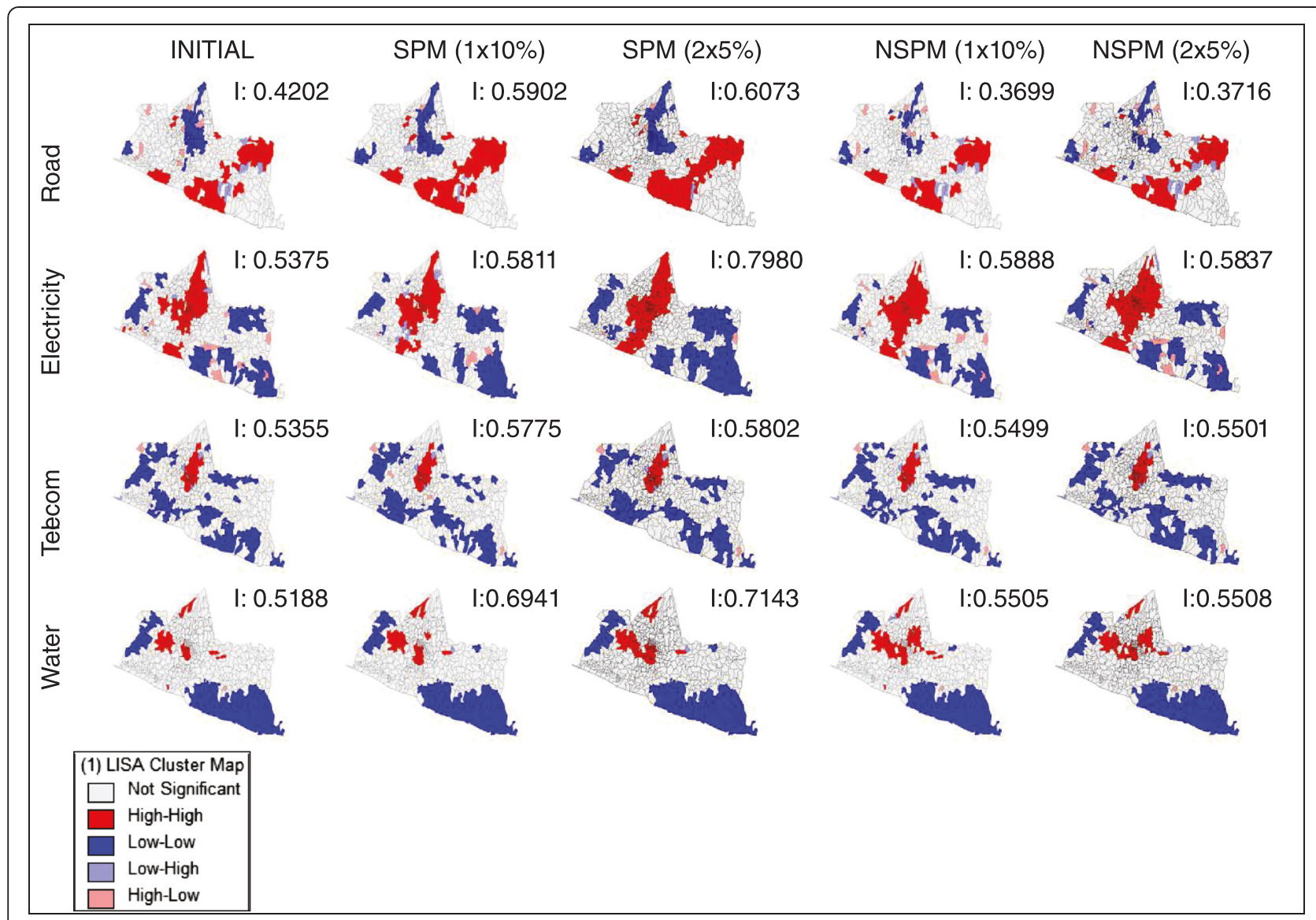

Fig. 5 Spatial equity at the initial level and after allocation with SPM and NSPM. Note: LISA, blue (or black in a b/w colour) represents low-low, red (or dark grey in a b/w colour) represents high-high, and Moran's I discloses that in general, spatial PM is more effective to address spatial equity

Table 6. Only a minor variance is found in water sector under $2 \times 5 \%$, which indicates group of villages that severely lacking of water clustered in similar location as shown in LISA map. Such situation makes SPM that seeks for neighborhood inequity is less senstitive than NSPM. Moreover, a lower result on $2 \times 5 \%$ simulation indicates that people satisfaction is higher to a distribution which provided in one delivery than two.

With $10 \%$ growth, the SPM generates a higher total utility. Hence, in general, the SPM performs better than the NSPM. This effect corresponds with the result on growth averages. In a utilitarian, context the total utility

Table 6 Utilitarian total equality

\begin{tabular}{lllll}
\hline & Growth : & $1 \times 10 \%$ & Growth: & $2 \times 5 \%$ \\
\hline Sectors & SPM & NSPM & SPM & NSPM \\
ROAD & 222,764 & 201,067 & 184,256 & 183,320 \\
ELECT & 108,390 & 104,879 & 100,323 & 100,042 \\
TELEC & 450,157 & 399,967 & 359,916 & 338,996 \\
WATER & 153,582 & 138,290 & 131,164 & 132,113 \\
\hline
\end{tabular}

indicates that SPM is the preferred choice of target beneficiaries.

\section{Non-utilitarian}

\section{Graphical result of curve dominance analysis}

The curve comparison (Fig. 5) shows continuous and discontinuous lines, which, respectively, indicate distinctive patterns of SPM and NSPM. For clarity, the initial situation (before allocation) is not presented in the graph. The results of $1 \times 10 \%$ and $2 \times 5 \%$ show similar patterns. Using the curves, an intuitive interpretation of poverty incidence, its severity and inequality problems can be obtained.

Among the four types of infrastructures, two of them produce similar patterns (i.e., telecommunications and water in Fig. 6). Both consistently depict that at the beginning of curve, at the left-most side of gaps, NSPM perform better than SPM. Meanwhile, at the right-most side, SPM performs better.

This similar pattern, except for the left side, can also be found for electricity infrastructure. However, a distinct 


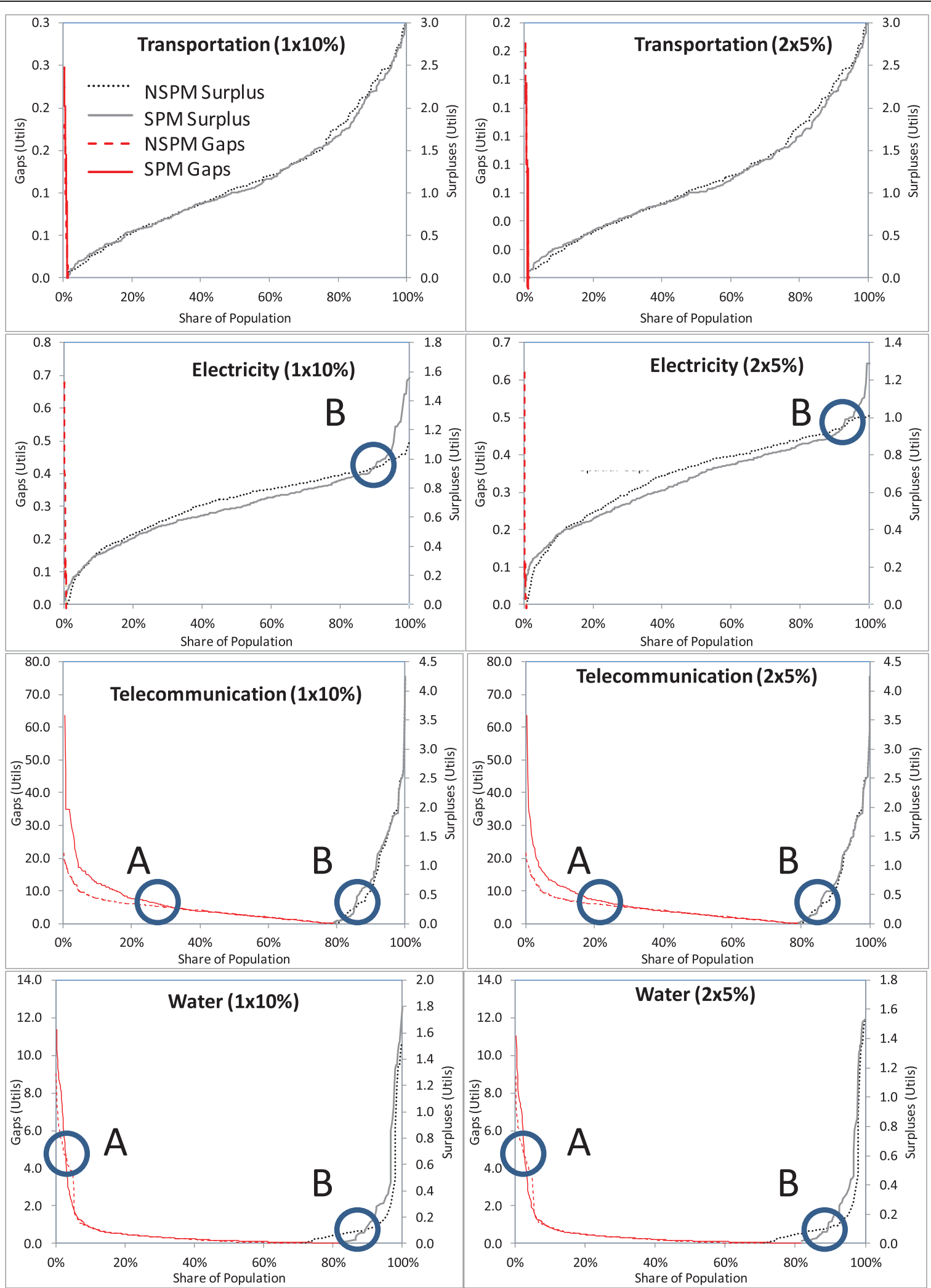

Fig. 6 Curve dominance analysis, which discloses the similarity of patterns in the telecommunications and water infrastructures 
irregular patterns is found for transportation. The possible source of this behaviour is the way infrastructure services are delivered, as explained in the discussion section below.

\section{Quantitative result of curve dominance analysis}

In addition to pattern observations, a quantitative analysis is provided. Tables 7, 8, 9 and 10 present the variation of SPM and NSPM to the level of poverty incidence, severity and inequality among the poor and the rich and its level of prosperity.

In addressing poverty, SPM and NSPM do not always result in similar distributional patterns. For example, SPM is more effective in reducing the poverty incidence in the road and electricity infrastructures but not in the telecommunications and water supply infrastructures, the sectors where a dominant of low-low cluster of severe poverty found.

A similar variation is also found in the effect of reducing maximum severity. Except for electricity infrastructure, NSPM is more effective in reducing the severity of the poorest, and it works best for the poorest in telecommunications (Table 8). Based on its distribution mechanism, the results in Tables 7 and 8 indicate that the poorest are located in approximately the same location and form a cluster of similarity and the local inequality is not recognized.

In terms of addressing equitable allocation, SPM also perform better, there is minor variation where NSPM slightly perform better than SPM to the poor groups (see Table 9). Meanwhile, for the rich groups, the SPM consistently performs better than the NSPM for all infrastructure sectors. An unexpected result, however, is found where both SPM and NSPM produce a higher level of inequality in rich groups than the initial condition (Table 9). The source of such anomaly is explained in the discussion section.

When looking at the effect on the richest groups (Table 10), although SPM performs better, less variation is found. However, for the roads and telecommunications infrastructures for both SPM and NSPM, there is no effect on the richest. The fact that SPM affects the richest in the electricity and water infrastructures indicates that not only is the allocation is pro-poor but it also pays attention to the group that could be promoting growth.

Table 7 Poverty incidence

\begin{tabular}{llllll}
\hline & Initial & Growth: & $1 \times 10 \%$ & Growth: & $2 \times 5 \%$ \\
\hline Sectors & & SPM & NSPM & SPM & NSPM \\
ROAD & 9.25 & 1.25 & 1.37 & 1.13 & 1.37 \\
ELECT & 4.13 & 0.19 & 0.7 & 0 & 0.65 \\
TELEC & 82.09 & 79.59 & 79.51 & 79.48 & 79.51 \\
WATER & 91.83 & 81.69 & 70.77 & 80.54 & 69.88 \\
\hline
\end{tabular}

Table 8 Maximum severity

\begin{tabular}{llllll}
\hline & Initial & Growth: & $1 \times 10 \%$ & Growth: & $2 \times 5 \%$ \\
\hline Sectors & & SPM & NSPM & SPM & NSPM \\
ROAD & 1.24 & 0.25 & 0.18 & 0.14 & 0.16 \\
ELECT & 2.5 & 0.08 & 0.68 & 0 & 0.62 \\
TELEC & 95 & 71 & 21.64 & 71 & 21.4 \\
WATER & 17.38 & 12.2 & 10.2 & 12.0 & 10.11 \\
\hline
\end{tabular}

Another interesting result is the similarity of patterns among the electricity, telecommunication and water infrastructures, which does not exist for road transportation (see Table 10). For these infrastructures, the curves cross each other at Points A and B (Fig. 6), with the exception of electricity, which crosses only at B. These patterns and their source of variation require careful observation, as is done in the discussion section.

\section{Discussion}

With reference to the indicators listed in the evaluation matrix (Table 4), the results confirm that in general, spatial preference modelling (SPM) for resource allocation is more in accordance with the theories of welfare than non-spatial preference modelling (NSPM). Some evidence is discussed here.

With regard to utilitarian theory, we found that SPM performs better than NSPM for both the redistribution of growth (Table 5) and total utilitarian equality (Table 6). This conclusion applies for all types of infrastructure.

The SPM also performs consistently better to serve non-utilitarian perspectives, particularly for infrastructure characterized with a linear type of network (see system characteristics in Table 1). For example, in reducing poverty incidence (Table 7), SPM works better for the road and electricity infrastructures. These infrastructures that are formed by networks of a linear typology tend to be more sensitive to SPM than infrastructure networks of plane or space typologies. These space typologies occur when the network creates similar level of service between locations in close proximity (e.g., wireless telecommunication and groundwater) and have no issue with local spatial inequity.

Further evidence that SPM works better for linear types of networks is the result of the equality of electricity and telecommunications of the poor groups (Table 9, poor section). Here SPM reduced the poor inequality in a place where incomplete network of linear infrastructure found in the cluster of poverty.

Moreover, in another inequity assessment, particularly for rich groups (Table 9, rich section), SPM also works consistently better than NSPM in all types of infrastructure. 
Table 9 Poor and rich inequality

\begin{tabular}{llllllllllll}
\hline Poor Inequality: & Initial & Growth: & $1 \times 10 \%$ & Growth: & $2 \times 5 \%$ & Rich Inequality: & Initial & Growth: & $1 \times 10 \%$ & Growth: & $2 \times 5 \%$ \\
\hline & & SPM & NSPM & SPM & NSPM & & & SPM & NSPM & SPM & NSPM \\
ROAD & 0.09 & 0.07 & 0.06 & 0.05 & 0.07 & ROAD & 0.09 & 0.07 & 0.08 & 0.07 & 0.08 \\
ELECT & 0.08 & 0.00 & 0.05 & 0 & 0.04 & ELECT & 0.06 & 0.05 & 0.05 & 0 & 0.04 \\
TELEC & 0.11 & 0.1 & 0.08 & 0.1 & 0.08 & TELEC & 0.12 & 0.13 & 0.14 & 0.14 & 0.14 \\
WATER & 0.14 & 0.14 & 0.13 & 0.13 & 0.13 & WATER & 0.18 & 0.21 & 0.3 & 0.21 & 0.3 \\
\hline
\end{tabular}

More supportive evidence for SPM is obtained from spatial equity assessment, which reveals that generally, SPM performs better than NSPM, as indicated by Moran's I in Fig. 5. SPM addresses spatial inequity by increasing Moran's I indexes. Even, with two-steps iteration (2x5 \%), SPM is much more effective in addressing spatial inequity.

One observable fact where the NSPM performs better that SPM is on Poverty Incidence of Water (Table 7). This is another evidence that in the case of water, the poorest group are located in same area, where no water network is available and the water lacking cover a wide area of the region (see the Low-Low cluster of Water in Fig. 5). In such cases, as no local spatial inequality is detected, SPM with a global or goal standardization (Wismadi et al. 2013) might be applied.

This observation also disloses that the typology of infrastructures also determines the effectiveness of certain types of preference modelling. Infrastructures that combine various typologies also require more attention to the implementation of spatial preference modelling. In addition, in an underdeveloping region, the incomplete network of the linear infrastructure tends to generate more spatial inequity. In this case, SPM helps find areas with lower connectivity or an incomplete network structure (e.g., missing links on a road network, underserved urban areas from piped water or fibre optic networks). The curve dominance analysis in Fig. 6 also enriches this observation. The left-hand side of point A (Fig. 6, telecommunications and water) indicates the worst-off groups that live in low-low clusters, whereas on the right-hand side of point $B$, areas where spatial inequity exists are indicated.

In terms of network development, the right-hand side of $\mathrm{B}$ also indicates that incomplete linear networks (e.g., fibre optic or copper networks, electricity grids or water pipe networks) exist and create gaps between

Table 10 Maximum prosperity

\begin{tabular}{llllll}
\hline Sectors & Initial & Growth: & $1 \times 10 \%$ & Growth: & $2 \times 5 \%$ \\
\hline & & SPM & NSPM & SPM & NSPM \\
ROAD & 3.4 & 3.4 & 3.4 & 3.4 & 3.4 \\
ELECT & 1 & 1.56 & 1.13 & 1.29 & 1.01 \\
TELEC & 4.25 & 4.26 & 4.26 & 4.26 & 4.26 \\
WATER & 1.53 & 1.79 & 1.53 & 1.79 & 1.53 \\
\hline
\end{tabular}

spaces. Meanwhile, on the left-hand side of A, the linear networks that have not reached the location result in low-low clusters (e.g., poor wireless network in rural areas, or wells in area with groundwater scarcity). The space between A and B indicates that a combination of systems are in place (i.e., linear network of copper and wireless, or water pipes and wells in each household) and produce an average level of service.

This A/B pattern is not found for transportation. This irregularity discloses that the road network does not necessarily determine a linear type of network because the predominated private vehicles cover a few public transport routes and turn the linear type into plane. Moreover, a complete road network in urban areas does not guarantee high performance due to traffic congestion.

In addition to the above general conclusion, there are some interesting findings. First, an anomaly is found regarding road infrastructure in the inequality of the poor group (Table 9, road), where NSPM works better than SPM. This peculiarity, however, is explainable by the fact that the linear infrastructure of roads does not determine the linearity of the service. The absence of public transport services (which is supposed to be linear in nature) causes the poor groups to have to rely on limited personal mobility and forms a network similar to space typology. A similar observation is found in rural areas, where the poor are mostly located: The issue in electricity and telecommunication could be access to networks, whereas for road and water, the issue is the availability of service. This nature of the problem might determine the type of networks in a specific location.

Therefore, in the case that the poorest are located in the same area and no specific neighbourhood inequality is recognized, the NSPM would work better in addressing the worst-off (the poorest), e.g., roads, telecommunications and water, in Table 8. The fact that telecommunication and water infrastructures (Table 7) appear more sensitive to NSPM indicates that similar levels of poverty are clustered. Figure 6 confirms this finding, where lowlow clusters of telecommunications and water infrastructures are more dominant than the other infrastructures.

Another interesting observation can be found in in Table 9 regarding the rich, where it is shown that for telecommunications and water, the rich inequality level is initially lower than after allocation. This unexpected 
finding is explainable: It indicates that some poor people become non-poor due to the allocation. These new near-poor groups, approximately $3 \%$ resp. $20 \%$ in telecommunications and water (see Table 7), contribute to inequality among the rich.

In the case of the rich groups (Table 10), both types of preference modelling do not affect this group for road and telecommunication, but the SPM in particular increases the level of service performance of the richest in electricity and water infrastructures. These findings indicate that in the case of electricity and water with $10 \%$ growth, SPM allows for the rich group to benefit from the growth.

Furthermore, the zero value of poor inequality for electricity (Table 9) reveals that with $10 \%$ growth, SPM could reduce more poverty incidences, whereas NSPM leaves more people and villages in poor condition. It also implies that in the case of linear infrastructure has provided sufficient level of service and only left small group of people and villages under poverty line (e.g., electricity), SPM could effectively alleviate deprived villages and poor people to become non-poor, for example, by connecting the villages to its better off neighboorhood.

In conclusion, this discussion outlines a list of evidence that SPM performs better than NSPM not only in satisfying various perspectives of welfare but also in providing new tools to observe infrastructure operational issues on the ground.

\section{Conclusion}

We disclose that spatial preference modelling is in compliance with the moral philosophy of both utilitarian and non-utilitarian theories. In general, SPM performs better than NSPM to achieve inequitable growth; however, the combination of both might be necessary with consideration of the level of infrastructure development, the typology of the infrastructure and the initial level of social and spatial equity.

Moreover, this research provides a good basis for generalizing the application of preference modelling for equity-based resource allocation for infrastructure and contributes to the debate of "people-centred" versus "place-base" development (Deichmann et al. 2011).

\section{Competing interests}

The authors declare that they have no competing interests.

\section{Authors' contributions}

AW performed the modelling and simulation and wrote the initial manuscript. $M B$ and $M Z$ developed the research framework, guided the research and revised several versions of the manuscript. MvM scrutinized the curve dominance analysis formulation. All authors read and approved the final manuscript

\section{Acknowledgements}

This publication is part of the INDF (Indonesian Facility) project supported by the Netherlands Government, for establishing an MSc Program in Management of Infrastructure and Community Development - MICD (http://pipm.pasca.ugm.ac.id). The research is jointly conducted by Faculty of ITC, University of Twente and Keypoint Consultancy BV in the Netherlands with The Center for Transportation and Logistics Studies Gadjah Mada University (Pustral-UGM) in Indonesia.

\section{Author details}

${ }^{1}$ Faculty of Geo-Information Science and Earth Observation, University of Twente, Enschede, the Netherlands. ${ }^{2}$ PUSTRAL (Center for Transportation and Logistics Studies), Universitas Gadjah Mada, Kemuning M-3, Sekip, Sleman, 55281 Yogyakarta, Indonesia. ${ }^{3}$ Centre for Transport Studies, University of Cape Town, Rondebosch, South Africa.

Received: 3 July 2015 Accepted: 24 September 2015

Published online: 15 October 2015

\section{References}

Ananda J, Herath G (2009) A critical review of multi-criteria decision making methods with special reference to forest management and planning. Ecol Econ 68(10):2535-2548. doi:10.1016/j.ecolecon.2009.05.010

Anselin L (1995) Local Indicators of Spatial Association-LISA. Geogr Anal 27(2):93-115. doi:10.1111/j.1538-4632.1995.tb00338.x

Araral E (2009) Privatization and regulation of public services: A framework for institutional analysis. Policy and Society 27 (3):175-180. doi:http://dx.doi.org/ 10.1016/j.polsoc.2008.10.008

Beedasy J, Whyatt D (1999) Diverting the tourists: a spatial decision-support system for tourism planning on a developing island. Int J Appl Earth Obs Geoinf 1(3-4):163-174. doi:10.1016/s0303-2434(99)85009-0

Benferhat S, Dubois D, Kaci S, Prade H (2006) Bipolar possibility theory in preference modeling: Representation, fusion and optimal solutions. Inf Fusion 7(1):135-150. doi:10.1016/j.inffus.2005.04.001

Berrebi ZM, Silber J (1989) Deprivation, the Gini index of inequality and the flatness of an income distribution. Math Soc Sci 18(3):229-237. doi:10.1016/ 0165-4896(89)90032-2

Bissonnette L, Wilson K, Bell S, Shah TI (2012) Neighbourhoods and potential access to health care: The role of spatial and aspatial factors. Health Place 18(4):841-853. doi:10.1016/j.healthplace.2012.03.007

BPS (2006) PODES (Potensi Desa). BPS-Statistics Indonesia, Jakarta.

BPS (2014) Gini Ratio Menurut Provinsi Tahun 1996, 1999, 2002, 2005, 2007-2013. Biro Pusat Statistik. http://www.bps.go.id/linkTabelStatis/view/id/1493

Chakhar S, Mousseau V (2007) An algebra for multicriteria spatial modeling. Comput Environ Urban Syst 31(5):572-596. doi:10.1016/ j.compenvurbsys.2007.08.007

Chandola T (2012) Spatial and social determinants of urban health in low-, middle- and high-income countries. Public Health 126 (3):259-261. http:// dx.doi.org/10.1016/j.puhe.2011.12.008

Chen A (2010) Reducing China's regional disparities: Is there a growth cost? China Econ Rev 21(1):2-13. doi:10.1016/j.chieco.2009.11.005

Cloke P, Milbourne P, Widdowfield R (2001) The local spaces of welfare provision: responding to homelessness in rural England. Polit Geogr 20(4):493-512. doi:10.1016/s0962-6298(01)00004-x

Damodaran A (2008) Strategic risk taking: A framework for risk management. Wharton School Publishing, New Jersey, USA

Das A (2015) Autonomous but constrained: CBOs and urban upgrading in Indonesia. Cities 48:8-20. http://dx.doi.org/10.1016/j.cities.2015.05.009

Deichmann U, Gill I, Goh C-C (2011) Texture and tractability: the framework for spatial policy analysis in the World Development Report 2009. Camb J Regions Econ Soc 4(2):163-174. doi:10.1093/cjres/rsr010

Dolan P, Tsuchiya A (2009) The social welfare function and individual responsibility: Some theoretical issues and empirical evidence. J Health Econ 28(1):210-220. doi:10.1016/j.jhealeco.2008.10.003

Domshlak C, Hüllermeier E, Kaci S, Prade H (2011) Preferences in Al: An overview. Artif Intell 175(7-8):1037-1052. doi:10.1016/j.artint.2011.03.004

Dworkin R (1981a) What is equality? Part 1: Equality of welfare. Philos Public Aff 10(3):185-246

Dworkin R (1981b) What is Equality? Part 2: Equality of Resources. Philos Public Aff 10(4):283-345, doi:citeulike-article-id:680850 
Eliazar II, Sokolov IM (2012) Measuring statistical evenness: A panoramic overview. Physica A 391(4):1323-1353. doi:10.1016/j.physa.2011.09.007

Grubesic TH (2008) The spatial distribution of broadband providers in the United States: 1999-2004. Telecomm Policy 32(3-4):212-233. doi:10.1016/ j.telpol.2008.01.001

Lorant V, Thomas I, Deliège D, Tonglet R (2001) Deprivation and mortality: the implications of spatial autocorrelation for health resources allocation. Soc Sci Med 53(12):1711-1719. doi:10.1016/s0277-9536(00)00456-1

Malczewski J (2004) GIS-based land-use suitability analysis: a critical overview. Prog Plann 62(1):3-65. doi:10.1016/j.progress.2003.09.002

Maniquet $F$ (2004) On the equivalence between welfarism and equality of opportunity. Soc Choice Welfare 23(1):127-147. doi:10.1007/s00355-003-0244-8

Nussbaum M (2003) Capabilities as fundamental entitlements: Sen and social justice. Fem Econ 9(2-3):33-59. doi:10.1080/1354570022000077926

Ohana S (2010) Modeling global and local dependence in a pair of commodity forward curves with an application to the US natural gas and heating oil markets. Energ Econ 32(2):373-388. doi:10.1016/j.eneco.2009.08.015

Outhred H, Retnanestri M (2015) Insights from the Experience with Solar Photovoltaic Systems in Australia and Indonesia. Energy Procedia 65:121-130. http://dx.doi.org/10.1016/j.egypro.2015.01.044

Pen J (1971) Income distribution: facts, theories and policies. Praeger Publishers, New York, USA

Perny P, Roy B (1992) The use of fuzzy outranking relations in preference modelling. Fuzzy Sets and Syst 49(1):33-53. doi:10.1016/0165-0114(92)90108-g

Phua M-H, Minowa M (2005) A GIS-based multi-criteria decision making approach to forest conservation planning at a landscape scale: a case study in the Kinabalu Area, Sabah, Malaysia. Landsc Urban Plan 71(2-4):207-222. doi:10.1016/j.landurbplan.2004.03.004

Piccolo D, D'Elia A (2008) A new approach for modelling consumers' preferences. Food Qual Prefer 19(3):247-259. doi:10.1016/j.foodqual.2007.07.002

Qizilbash M (2011) Sugden's critique of Sen's capability approach and the dangers of libertarian paternalism. Int Rev Econ 58(1):21-42. doi:10.1007/ s12232-011-0112-2

Roberts F, Tsoukiás A (2009) Voting theory and preference modeling. Math Soc Sci 57(3):289-291. doi:10.1016/j.mathsocsci.2008.12.005

Rowley C, Abdul-Rahman S (2008) The Changing Face of Management in SouthEast Asia. Routledge, Abingdon.

Sager T (2011) Neo-liberal urban planning policies: A literature survey 1990-2010. Prog Plann 76 (4):147-199. http://dx.doi.org/10.1016/j.progress.2011.09.001

Sen A (1980) Equality of What? In: Sterling M. McMurrin (ed), The Tanner Lectures on Human Values, Vol. I. Cambridge, U.K: Cambridge University Press, 257-280.

Sen A (2004) Capabilities, Lists, and Public Reason: Continuing the Conversation. Fem Econ 10(3):77-80. doi:10.1080/1354570042000315163

Simon HA (1960) The new science of management decision. Harper and Row, New York.

Smith DM (1977) Human geography: a welfare approach. Edward Arnold, London.

Son HH, Kakwani N (2008) Global Estimates of Pro-Poor Growth. World Dev 36(6):1048-1066. doi:10.1016/j.worlddev.2007.10.002

Sovacool BK (2013) Expanding renewable energy access with pro-poor public private partnerships in the developing world. Energy Strategy Reviews 1 (3):181-192. http://dx.doi.org/10.1016/j.esr.2012.11.003

Sudgen R (2006) What We Desire, What We Have Reason to Desire, Whatever We Might Desire: Mill and Sen on the Value of Opportunity. Utilitas 18(01):33-51. doi:10.1017/S0953820805001810

Tsou K-W, Hung Y-T, Chang Y-L (2005) An accessibility-based integrated measure of relative spatial equity in urban public facilities. Cities 22(6):424-435. doi:10.1016/j.cities.2005.07.004

Tsoukias A (1991) Preference modeling as a reasoning process: A new way to face uncertainty in multiple criteria decision support systems. Eur J Oper Res 55(3):309-318

UNDP (2008) Malaysia measuring and monitoring poverty and inequality. United Nations Development Programme, Malaysia

Wang F, Arnold MT (2008) Localized income inequality, concentrated disadvantage and homicide. Appl Geogr 28 (4):259-270. http://dx.doi.org/ 10.1016/j.apgeog.2008.07.004

Wismadi A, Zuidgeest M, Brussel M, van Maarseveen M (2013) Spatial Preference Modelling for equitable infrastructure provision: an application of Sen's capability approach. J Geogr Syst. doi:10.1007/s10109-013-0185-4

Xiang W-N (2001) Weighting-by-choosing: a weight elicitation method for map overlays. Landsc Urban Plan 56(1-2):61-73. doi:10.1016/s0169-2046(01)00169-4
Yigitcanlar T, Lee SH (2014) Korean ubiquitous-eco-city: A smart-sustainable urban form or a branding hoax? Technological Forecasting and Social Change 89:100-114. http://dx.doi.org/10.1016/j.techfore.2013.08.034

Yitzhaki S (2002) Do we need a separate poverty measurement? Eur J Polit Econ 18(1):61-85. doi:10.1016/s0176-2680(01)00069-6

Yuan J-H, Kang J-G, Zhao C-H, Hu Z-G (2008) Energy consumption and economic growth: Evidence from China at both aggregated and disaggregated levels. Energ Econ 30(6):3077-3094. doi:10.1016/j.eneco.2008.03.007

Zhang Y (2014) From State to Market: Private Participation in China's Urban Infrastructure Sectors, 1992-2008. World Dev 64:473-486. http://dx.doi.org/ 10.1016/j.worlddev.2014.06.023

\section{Submit your manuscript to a SpringerOpen ${ }^{\odot}$ journal and benefit from:}

- Convenient online submission

Rigorous peer review

- Immediate publication on acceptance

- Open access: articles freely available online

- High visibility within the field

- Retaining the copyright to your article

Submit your next manuscript at $>$ springeropen.com 